\title{
The Development of the ERMA Banking System: Lessons from History
}

\author{
AMY WEAVER FISHER \\ JAMES L. MCKENNEY
}

\begin{abstract}
In the early 1950 s banking was faced with a paper-handling crisis. Banks were unable to keep on top of the rising number of checks and were unable to retain bookkeeping staff. Bank of America, then the largest bank in the world. tumed to Stanford Research Institute to develop an automated bookkeeping and proofing system. SRI and BofA worked together to create ERMA (electronic recording machine - accounting) and to develop the MICA (magneticink character recognition) check coding system. The work on this project demonstrates the necessity of senior executive involvement, strong leadership, and innovative engineering.
\end{abstract}

n the early 1950 s, the banking industry was on the brink Lof a crisis. Between 1943 and 1952, check use in the United States had doubled from four billion to eight billion checks written every year. Bankers projected by 1955 the number of checks would be increasing by approximately one billion per year, and, by 1960,14 billion checks would be writter each year. This dramatic increase in checking (shown in Figure 1) led to a substantial, twofold problem for the industry: The paperwork was staggering and banks were unable to retain bookkeeping staff. This situation had banks at a standstill; they were able neither to expand, nor, in some cases, even to keep pace with the increasing flow of paper.*

The overwhelming growth of paperwork at the banks was created by the check-clearing process. Each of the 28 million checks written every business day passed through approximately two and one-third banks, taking more than two days to be processed. This led to a staggering 69 million checks in process throughout the United States banking system on an average day. ${ }^{3}$ Unless a check was deposited at the bank where both accounts were located, the check had to be sorted by hand and individually rung up on an adding machine a minimum of six times during the clearing process. $^{\text {t }}$

In a 40-person branch, at least seven people were employed as full-time clerical workers. Most were young female bookkeepers between the ages of 18 and 24 . Their monotonous work mainly consisted of sorting pieces of paper, running an adding machine, and bundling checks. Not surprisingly, considering the dradgery of the position and the age of the women, who traditionally left the banks upon marrying, the turnover rate was exceedingly high - in some areas reaching 100 percent turnover each year. ${ }^{4}$

First in a series about computer use at Bank of America.
Once a check was deposited at a bank, two things needed to be accomplished quickly: proofing and bookkeeping Proofing was done to identify the originating bank or branch and verify the amount on the check. Checks, identified only by signature, were received in batches by the tellers and given in batches to proof-machine operators. The operator keyed in the number of the issuing bank and the amount for each check. The proof machine then fed the check into one of as many as 32 pockets associated with the number of the bank. An adding machine attached to each pocket printed the amount of the cbeck, the total for each pocket, and a running grand total on a paper tape. One of the pockets was reserved for "on us" checks - those written by customers whose accounts were with the bank. It was necessary to finish proofing early to catch stop payments or overdrafts on accounts.

At the end of each day, the checks in each pocket (excepting the "on us" checks) were removed, packaged with the adding tape from the pocket, and forwarded to the Federal Reserve system for distribution to the issuing banks. At each routing step the checks again passed through proof machines and were accumulated into new batches with control tapes. Once the checks were distributed by the Federal Reserve, the receiving bank added these to its "on us" checks and processed them accordingly. In general, the proofing system was manual, subject both to operator mistakes and to machine errors even when the operator performance was perfect.

* The high rate of checking was only one part of the trend toward consumer banking that added to banks" paper-handling woes. Consumer loans, bome loans, auto loans, and other lines of credit, as well as personal checking accounts, were becoming readily available for a large part of society. In the postwar era, savings accounts increased 33 percent, commercial loans increased 113 percent. mortgages increased 290 percent, and consumer installment credit increased 850 percent. ${ }^{2}$ 


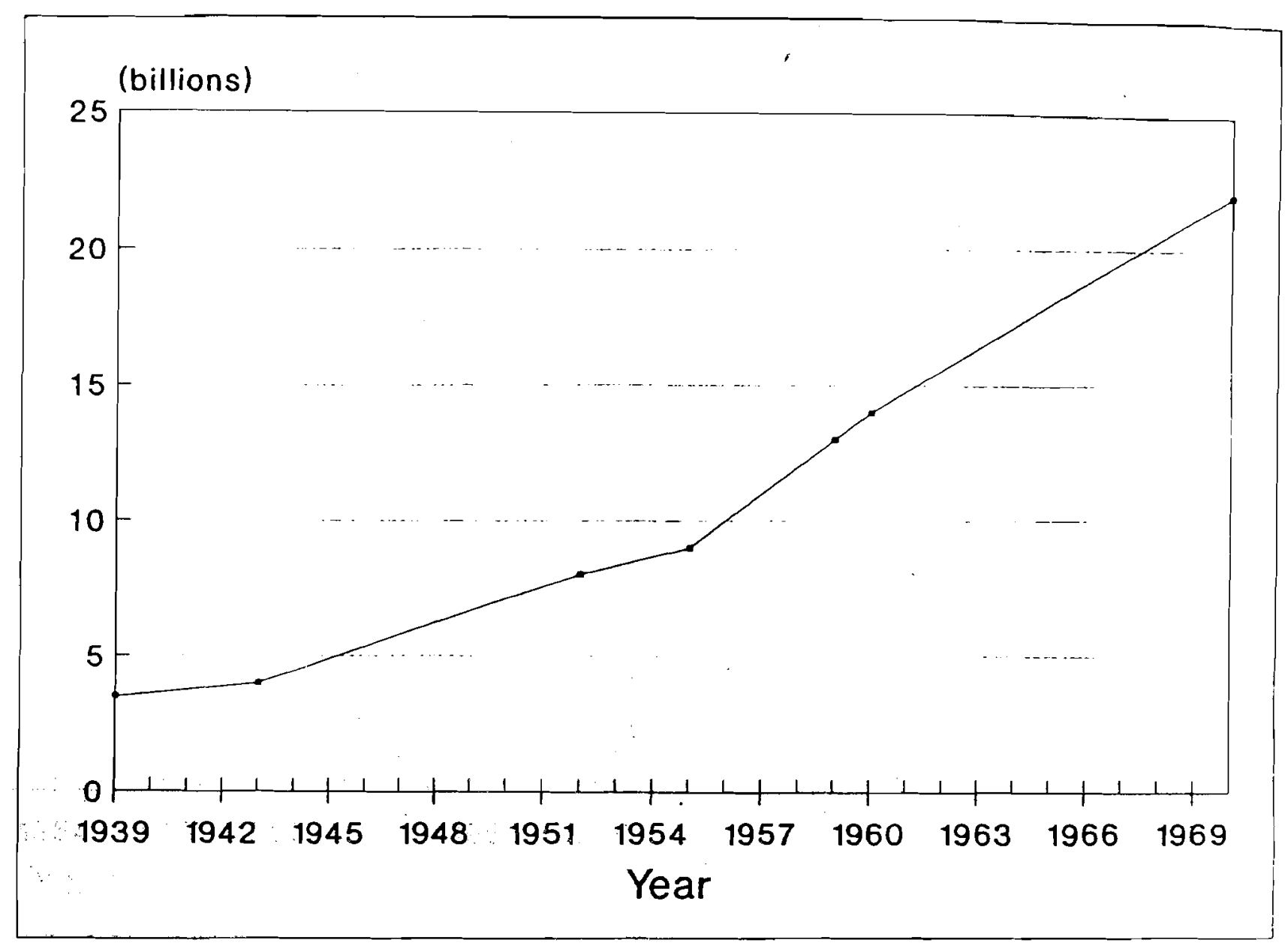

Figure 1. Checks written in the US from 1939 to 1969.

Bookkeeping consisted of manually keeping a customer's account balance up to date daily according to deposits and withdrawals. Each afternoon, "on us" checks were sorted to accounts on the basis of signature and taken to a conventional ledger-card accounting machine, where the amount of the check was subtracted from the balance and a new balance noted and posted to the account's ledger by an operator. A copy of the ledger card and the checks were mailed to the depositor as the monthly statement, and a ledger card with the new balance was saved for the next month's cycle. Timing was very important in this process. Each morning the banks received checks processed by the Federal Reserve that had to be debited from the check writer's account. In the afternoon, banks exchanged all except the "on us" pile of checks with other banks in the same city. Most banks were forced to shut their doors to business at 3:00 p.m. each day to handle the daily bookkeeping and proofing needs.

\section{Bank of America}

Bank of America (Bof A), called Bank of Italy until 1930 , was started by A.P. Giannini in San Francisco in 1904 as a small neighborhood savings and loan. Giannini's philosophy was to provide banking services to those not traditionally served by local banks. His success was phenomenal. In
1909, Giannini opened his first branch bank in San Jose; by the end of 1918, there were 24 branch banks stretching from one end of California to the other. By its 25 th anniversary. in 1929. Bof A had 292 branches, employed more than 7.000 people, and had more than $\$ 1$ billion in assets.

In 1936, the elder Giannini passed the reins to his son. L.M. Giannini. By the end of 1941, Bank of America boasted 495 branches and $\$ 2.1$ billion in assets. ${ }^{6}$ During the Second World War, California's population and economy mushroomed, boosting Bank of America's resources io more than $\$ 5$ billion - more than any commercial bank in the world. After the war, the younger Giannini augmented his strong "Banca d'America e d'Italia" subsidiary by opening nine offices overseas. ${ }^{7}$ By 1945, Bof A was the largest bank in the world.

S. Clark Beise, senior vice president of BofA in 1950 (and later president from 1954 to 1964), had been invited personally by A.P. Giannini to leave his position as a national bank examiner and join Bank of America as a vice president. According to bank legend, Giannini had told Beise, "I'd like you to come into the bank. You'll find the way free to the top. $^{\text {n8 }}$ Beise was acutely aware of the serious problems facing the nation's banks in general and Bank of America in particular. He had a keen interest in technology and automation as a means to continued growth and became an 
active leader in computer-based innovations at Bof $\mathrm{A}$. He saw the checking crisis as an obstacle to growth, and became the first person among senior management to realize that the solution lay in automating the check-handling system and to take the initiative in exploring methods to automate check-handling procedures

\section{Stanford Research Institute}

In 1950, Stanford Research Institute (SRI)* of Menlo Park, California, began to work on an automation solution to BofA's check-handling problem. SRI had been founded in 1946 as a nonprofit research center with a mission to conduct applied research on the West Coast. The institute had three main research divisions: physical sciences, economics, and engineering. 9 In the spring of 1950 , three executives from SRI led by Dr. W.B. "Hoot" Gibson spent a morning conducting a promotional visit to the Emporium department store. The Emporium meeting took place near Bank of America headquarters, and when the meeting ended earlier than expected, Gibson decided to call on Berse, whori he knew slightly. Gibson later recalled:

I told Beise that this was just a "shot in the dark," but that I thought Bank of America should be thinking about electronic applications... He expressed some concern about whether the bank would ever get what was really needed from IBM, Burroughs, and other such companies. I left the meeting after about five minutes - and the only thought left was maybe the bank should look into the situation further. Within a few days I heard the bank had contacted Tom Morrin [SRI's director of engineering rese arch], and that this had been done at my suggestion. ${ }^{10}$

Beise acted quickly on Gibson's advice. Due to its size, the growth in checking was affecting Bank of America severely. Bof $A$ 's checking accounts were increasing at the rate of 23,000 new accounts per month." By 1950, Bof A managed over 4.6 million checking, savings, and Timeplan accounts. ${ }^{7}$ Bank management realized that "growth would not be limited by new business, but rather by...being unable to adequately service new accounts. "I Beise had been considering this problem carefully and had approached several business-equipment manufacturers about creating an automated bookkeeping system. But although the manufacturers were willing to improve their basic proof machine, none was interested in investing the time or capital to create an entirely new system. To Beise, SRI seemed the perfect solution. SRI could act as a research and development division to establish what was possible in automated check

\footnotetext{
- Stanford Research Institute was incorporated as an independent, not-for-profit corporation in the postwar era. The trustees of Stanford University elected the board of directors of the institute and the presideat of the university served as the ex officio chairman of the board. In 1970, all ties between Stanford Research Institute and Stanford University were severed, and the institute adopted its initials as its official name. The institute is currently known as SRI International. The terms SRI and Stanford Research Institute are used interchangeably in this aricle.
}

handling and to design a model to test or sell to a manufacturer.

Bof A vice president Frank M. Dana contacted Thomas H. Morrin to pursue an exploratory discussion about automating the bank's check-handling and bookkeeping sys tems. Representatives from Bank of America first met with SRI delegates in June 1950. when Dana arranged for Joseph Lovewell, an SRI economist, and Oliver Whitby, manager of systems engineering, to visit the bank's Palo Alto branch. ${ }^{12}$ The meeting provided the SRI men with a firsthand view of banking procedures and the magnitude of the paper crisis. Whit by gathered information, drew up several flow charts of the information-processing operations, and outlined a data-handling system.

Representatives from Bof A and SRI immediately began a series of meetings to discuss the steps involved in check. handling, account-numbering, and paper-handling systems. The conversation focused on how to automate these processes. The challenge was to develop a system that

could handle used paper, read data from this paper. and perform all the required bookkeeping operations. It was realized that the system [had to] be fast enough to allow all operations to be completed every day within the tight time schedule followed by banks, and that it [had tol be accurate - to the last penny. No undetected errors could be allowed: Furner, this work [needed to] be performed by automatic machinery, so that a high percentage of the tedious manual work could be eliminated - otherwise time schedules, growth potentials, and economic requirements could not be met. The equipment had to be sufficiently low in initial cost so that the cost of its operations and depreciation would be no more expensive than the present methods. ${ }^{13}$

Based on these initial discussions. Bof A and SRI agreed that the proposed system would perform five basic book keeping functions:

1. Credit and debit all accounts

2. Maintain a record of all Iransactions.

3. Retain a constant record of customer current balances to be printed as needed.

4. Respond to stop-payment and hold orders on checks.

5. Notify the operator if a check caused the account in question to be overdrawn. ${ }^{14}$

Neither proofing nor automatic sorting of checks was part of the original design. Based on Whitby's observations at branch offices, the system was to be located at a central office to service surrounding branches. The machine was envisioned as receiving items listed on a battery of approximately ten 10-key, double-register adding machines wired directly to a magnetic memory drum that would contain the account balances. Operators would key in the amounts of the checks. All checks bearing dates more than (wo months old would be checked automatically against the stop-payment file before being listed. ${ }^{15}$ 


\section{BofA and SRI}

Research on the BofA project began in earnest with operations conducted on two levels. SRI's Morrin was in charge and functioned at the same level as the executive bank management team of Dana, Beise, and Ranaulf Beames, vice president in charge of methods and chief liaison between SRI and Bank of America. Although none of the bankers was well versed in engineering, each clearly understood banking and the acute problems connected with the growth of checking. The next level of players included Bof A's Charles Conroy, assistant to Beames and an industrial engineer in the standards department, and Howard Leif, a comptroller, who watched over issues affecting standards and procedures. Leif and Conroy worked primarily with SRI systems engineers Whitby and Jerre Noe. Whitby came from Harvard University, Noe from Stanford, where each worked on university programs while obtaining his PhD degree. Noe and Whitby led the research throughout the initial systems studies. Noe, the head of SRI's engineering sciences division, was project leader throughout the program. These teams led the search for a technical solution to the increasingly severe bookkeeping problem.

From the beginning, SRI and Bank of America had symbiotic goals in wanting to work with one another. Beise needed a reputable organization, preferably local, to lend credibility to his futuristic goal of automated check processing. Traditional office-equipment manufacturers more familiar with banking had not stepped up to fill this need and, as Beise had noted in his original discussion with Gibson, he did not expect IBM, Burroughs, NCR, or other leaders in office machinery to take on the task any time soon. SRI was a sound choice to develop the system as it was local, well established, and associated with a prestigious university. For Tom Morrin and others at SRI, Bank of America was an equally desirable partner. BofA was large, highly respected; and willing to try some innovative technology to solve its current check-handling problems. In addition, SRI had recently acquired several computer-oriented engineers and was looking for an opportunity to "put [its] foot in the computer door." 16 Morrin viewed this venture as likely to yield results that might eventually be marketable to other organizations such as the United States Postal Service. ${ }^{16}$ Working together on an automation project served both Bank of America's and SRI's goals.

\section{The feasibility study}

In late July 1950, SRI was instructed to proceed with a feasibility study of an electronic bookkeeping machine to be designed and produced for Bank of America. The feasibility study involved an appraisal of three areas. First, the engineers would study the tight banking time schedule under which the machine would have to be run. Second, an analysis would be made of the encoding and retrieval of all the information the machine would have to handle for storage, processing, and printing. Third, alternative production and storage design would be reviewed to obtain reliable, prompt access to the accounts to provide up-to-date balance information for customers. Engineers evaluated existing tech- niques to process the information and considered how large a project the development would constitute. ${ }^{13}$ Beames emphasized that the machine should take over the majority of check-processing operations. His goals were to speed up the bookkeeping process while making it more accurate and reducing the number of employees. He also wanted to

\section{Bank of America considered the check to be an important emotional link to the customer and felt that few, if any, changes could be made to the check itself.}

minimize the space records were taking up and make the records easier to access. This study (and all further SRI/BofA work) was highly secretive. Only those engineers directly involved with the project at SRI were aware of it, and very few bank employees knew of its existence.

An important concern for Bank of America during the feasibility study was the check. Bof A considered it to be an important emotional link to the customer and felt that few, if any, changes could be made to the check itself. Bof A's rigidity on this issue became a major concern for the engineers, who felt changes were needed for a successful system. Noe and Whitby were pleased to discover after a few meet ings that despite BofA's initial stand, Beames was actually quite flexible. Noe noted positively in an internal SRI memo that Beames "apparently has been responsible for many of the "radical' changes made [at BofA] in the past." This tlexibility and willingness to work out tricky situations helped to ensure a strong working relationship between Bank of America and SRI representatives.

The first time a decision had to be made between customer use habits and system needs was when the engineers insisted that the account filing system be redesigned. Prior to the 1950 s, customer files were kept alphabetically. This alphabetic filing system meant that the order changed with the addition of any new account other than "Zzzzz." In addition, the only form of identification and verification on the check was the signature, which was checked against an index card with the customer's signature kept on file at the branch office. SRI suggested Bof A change to a numerical (or at least alphanumerical) accounting system for encoding and identification purposes. Numbering each account, independent of name, would allow for additions by automatically giving the highest number to the newest account. For Bank of America, the change would mean distributing all new checkbooks with each customer's name and number stamped in one corner (previous checks had no identifying marks). It also meant warning customers against loaning blank checks to friends, a common practice before automation. After much discussion, Beames said he did not object to this change and suggested that "the official point of view agreed - or could be made to agree - with his." 16 The change made the checking process easier to automate and provided a more reliable method of identifying the check. 


\section{Development of ERMA}

\section{Trade-offs}

While the feasibility study was being conducted, the engineers and bankers began to learn the complexities of each other's businesses. Beames was a hands-on manager and encouraged Whitby, Noe, and Fred Kamphoefner of SRI to make trips to branch and central bank offices to observe the facilities and processes. These trips demonstrated to the engineers the need for accuracy, and the narrow window after the bank closed and before it opened that was available to process checks, get the balances up to date, and return checks for lack of funds. Beames also stressed to SRI that banking was a service ind ustry with a customer focus. Prompt, reliable banking services encouraged customer loyalty. This underscored Bof $A$ 's conviction that the customer be inconvenienced as little as possible and use habits not be changed unless absolutely necessary.

Correspondingly, BofA representatives Beames, Cònroy, and Leif became acquainted with the basics of what a computer system could and could not do, the rigidity of computers, and the broad sweep of potential, but still unproven, applications. The computer industry was just beginning and its limits were not clearly defined. The bankers became aware of the trade-offs to be made between cost, function, and speed. They realized that certain applications were not possible or probable, while other processes could be eliminated through improved system design: They began to realize that automating the check-processing system would require more than installing a computer system; it would mean entirely reorganizing the way check processing was conducted.

There was ongoing discussion at this time about what the system should be: a bookkeeping machine, a proof machine, or a combination of both. Bookkeeping accounted for the change in the customer's balance and recorded the history of the transaction and the ending balance. The primary objective of proofing was to capture accurately and authenticate the amount of the check and the bank or branch identification. Originally, Bank of America was interested in attacking the bookkeeping problem only. But when the SRI engineers convinced Beames to assign customer numbers and place them on the checks, the ability to combine bookkeeping with the proofing function became evident. (Later developments in common machine language and magnetic ink made it possible to integrate the two features.) Adding the proofing, however, would confound the operational constraints of the system. Proofing was done throughout the day; then, at the close of the day, the "on us" checks were sorted and account balances updated. As the "system" was to be run centrally in batch mode, batch cycle time was the time between bank closing and opening minus travel time. Thus combining the two would require all checks to be forwarded to batch-processing centers, whereas for bookkeeping only the "on us" checks would be forwarded to the center and other checks to the distribution center. In small cities, as much as 90 percent of a local bank's checks might be "on us" checks: in metropolitan areas this percentage was considerably lower. Bank of America had such a large mar- ket share that "on us" checks ranged from 40 to 80 percent in different branches. ${ }^{18}$

\section{Feasibility study results}

In late September 1950, Morrin informed Beames that SRI's feasibility study was complete and "indicated it was technically possible to build an automatic bookkeeping system for ledger posting and processing of commercial checking accounts." Morrin suggested a three-phase approach to the project: 12

1. a study of banking procedures external to the machine,

2. general logical design, and

3. development, construction, and testing.

The third step would be carried out by an equipment manufacturer, not by SRI, since manufacturing ran counter to SRI's mission statement to conduct original research. This report first referred to the machine as the "E. R. M." electronic recording machine.

\section{The research and design contract}

In mid-November 1950, Beames presented Whitby with a contract for $\$ 15,000$ to be paid over a period of six months for phases 1 and 2 , with a note emphasizing that the ERM would have to perform both the proof and bookkeeping functions. Phases 1 and 2 covered the research and design of general logic for the system. Although not actually signed until late December, due to the amount of work done previously, the contract between $B$ of $A$ and SRI was back dated to November 1, 1950.19

After five months, SRI found the money insufficient for the work program and, in April 1951, Noe and Whitby met with Beames to request an additional $\$ 5,000$ to complete the project. Beames agreed and asked for the official report to be presented to him in mid-May. ${ }^{19}$ During this time, Noe and Whitby; together with SRI engineer John Davis and others, came up with a preliminary design for the machine and drew. logical-design block diagrams for each of the main ERM operations. Whitby noted that "this period of work saw a good deal of inventing, and many changes in the design to get out of holes." 19 The study involved a thorough investi. gation of the operational practices of the entire bank. with a careful analysis of the particular system requirements. Engineers worked to establish exactly what the machine needed to accomplish, including input and output data handling, size of temporary and permanent storage media, and arithmetic operations. ${ }^{12}$ On April 30, phases 1 and 2 were completed and SRI presented its interim report to Bof $A$.

Although Bank of America was interested in using the proofing process as an input to bookkeeping activities, the interim report still described the machine fundamentally as a bookkeeping device, with checks being proofed and sorted at the branches before delivery to the ERM. Once at the ERM center, operators would enter batches of checks through four input-output units into temporary storage. When a check entered the input-output unit, the machine would read the account number, which was to be printed on 
the check with fluorescent ink. Accounts would be updated and overdrafts noted. When the storage section was full, the information would be transferred to addressograph plates. A list of all transactions by account number would then be printed out, on an ordinary typewriter, for cross-checking. Another list specifying overdrafts and hold payments would be generated for branch managers. Once a month statements would be printed to be sent to customers. ${ }^{20}$ The system would automatically handle the production of statements and other documents needed by the bank and its customers. The ERM would have as its principal input units four modified adding machines. Each unit would have a printer and an automatic photoelectric reading device. The ERM would serve approximately 12 branches from a central location.

While the interim report was being considered by Beise, SRI began to estimate costs for constructing the ERM and the optimal account capacity. SRI originally came up with an estimate of $\$ 750,000$ for the machine, plus an additional $\$ 15,000$ for the development of a check reader for the entry machine. This rough estimate was made by comparing the estimated construction costs other companies incurred for large-scale computer projects such as the Mark III, UNIVAC, EDVAC, and Whirlwind I. Once the engineers broke down the ERM development into specifics, the final estimate came to $\$ 949,000$. This cost seemed high to Morrin, who suggested breaking the estimate down according to how much a minimum system (with only two reader/sorter devices and tapes) and a complete system (with 10 of each feature) would cost. The readjusted figures came to $\$ \$ 30,000$ for the minimum and $\$ 830,000$ for the complete system. ${ }^{19}$ ?

Account capacity was more difficult to estimate because of inadequate information on the cost of storage, access time, and tape length for the set of records. Consequently, SRI undertook a study of demand at San Francisco, Los Angeles, and other major areas and varied the size of the components of each system. On July 7, 1951, SRI recommended an optimum economical size of 30,000 accounts per ERM (double the original estimate of 15,000 accounts) to take advantage of the projected economies of scale by servicing more branches with each electronic recording machine.*

Beames requested the cost and capacity estimates so Beise could present the figures to potential machine manufacturers such as IBM, Burroughs, and AddressographMultigraph. These estimates were supposed to be SRI's final projects for Bank of America. SRI had completed its contract by showing the feasibility of the system, thoroughly researching the options, and designing the general logic. At this point Beise planned to turn the system design over to a business-equipment manufacturer to develop and sell.

\section{The Burroughs Corporation}

In the fall of 1951, Beise, along with A.R. Zipf, an experienced bank operations manager and innovator who later became a crucial player in the adoption of national

\footnotetext{
* Each account was allowed a monthly average of 1.56 items processed per account per day. ${ }^{20}$
}

banking standards, traveled to Burroughs, NCR, and other leading companies to interest them in building an ERM for Bank of America. ${ }^{21}$ However, they were only able to interest one manufacturing company. the Burroughs Corporation. in the SRI proposal. Bank of America considered a joint venture with Burroughs for the development of a high-

\section{Automating the check-processing system would require more than installing a computer system; it would mean entirely reorganizing the way check processing was conducted.}

speed printer and the adaptation of the Burroughs Sensimatic bank bookkeeping machine ${ }^{19}$ into an ERM system. After discussion with SRI, Beise and Beames flew to Detroit to meet with Burroughs officials. Soon afterward, three Burroughs officials, T.M. Butler, Ted Welch, and R.V.D. Campbell, flew to California to meet with Beames and SRI's Morrin, Noe, and Whitby: The more than seven hour meeting included detailed discussions of the printer. proof machine, and proposed ERM system.

Although the three panies seemed ready to sign a contract at this meeting, the official logbook kept by Oliver Whitby has only two entries mentioning Burroughs after this point. The first, dated November 1951, notes "some objections from Burroughs"; the second, 'one month later. reads "Burroughs out of picture as associate of Bank on ERM."22 Morrin maintains Beise used Burroughs as a means of checking up on SRI. SRI estimated it would cost Bank of America approximately $\$ 1$ million to complete the system. ${ }^{23}$ Burroughs estimated the system would actually cost double SRI's guess.

\section{Development at SRI}

After discussions with Burroughs fell apart, Beise asked SRI to go ahead with the construction of an engineering prototype of the ERM, a decision motivated in part by his belief that confidentiality could be better maintained working with SRI. SRI had never considered being an ERM supplier, since the research institute had no interest in manufacturing and was ill-equipped to build what was to become one of the largest and most complex computer systems yet designed..$^{24}$ Morrin remembers agreeing somewhat reluctantly to carry out the design and construction of the machine, believing it to be an inappropriate task for a research institute. Beise still anticipated selling the system design to a manufacturing company after SRI demonstrated the system's feasibility in a working prototype.

On January 28, 1952, Bank of America and SRI signed a contract for phase 3 of the proposal covering the development, construction, and testing of a pilot model ERM to provide service to 12 branches. SRI and BofA divided the effort into four stages:.14

1. Finish the logical design of remaining operations. 


\section{Development of ERMA}

2. Construct a pilot model.

3. Test the model at one of Bof A's branches, tentatively Menlo Park.

4. Finish and install the machine in the Berkeley branch to provide bookkeeping service for 12 nearby branches.

The contract specified that Bank of America would pay SRI no more than $\$ 850,000$ over four years, with an additional $\$ 25,000$ for subcontracts. Although the final expenses were never released. most engineers estimate that the grand total was actually around $\$ 10$ million. ${ }^{25}$

Once the decision had been made to have SRI develop the system, Morrin and Noe began meeting regularly with Beise at Bank of America headquarters, where bank employees who knew about the project referred to them as the "whiz kids." 23 Beise took an active role in guiding the project and formally reviewed the work every three months. Although he had no background in information systems; Beise was a demanding hands-on manager who wanted to know everything that was going on. Morrin and Noe both remember his piercing questioning and strong leadership. ${ }^{9}$ Beames. Conroy, and Robert Reilly also began spending considerable time at SRI, while Zipf continued to study the computer industry throughout the country. The project took up a large portion of SRI's space and time: More infrastructure and engineers were required.

After signing the contract for phase 3, SRI, not being a production company, began to look for other companies to develop peripheral ERM-tailored equipment. This included tailored electronics packages, magnetic-tape transports and drums, a sorter-reader machine, and a high-speed output printer. ${ }^{14}$ To ensure a steady future supply of these products, Bof $A$ and SRI believed it was wiser to have a known officeequipment manufacturer produce them. All other ERM $\infty \mathrm{m}$ ponents could be developed by SRI or purchased through regular channels. The sidebar on page 51 lists the companies considered for each piece of peripheral equipment.

SRI launched a far-ranging technology search and visited more than 15 companies around the United States and Europe to observe products and assess each company's willingness to develop and produce specific ERM components. Much of the component selection and quality control was handled by $C$. Bruce Clark. To maintain confidentiality, the companies generally were not told the details of the overall system, only the specific functional requirements they had to meet.

\section{Changes in the plans}

By the fall of 1952, the design and operation of the ERM was well defined. The primary system was to have four 30,000-account capacity ERM machines located in a central office, which would be linked to approximately 12 branches by messenger service (in some cases a flying messenger service). Each ERM was to be operated by 10 to 12 bookkeepers and handle both bookkeeping and proofing functions. The addition of the proofing function was requested by the bank. The printer was to be a separate unit from the main machine. Customer names and addresses were to be stored on magnetic tape. Finally, plans were made to use the completéd SRI system to process BofA checks rather than have it serve only as a prototype. ${ }^{22}$

A significant change in the project leadership occurred in May 1952 with the death of Beames. the chief liaison between SRI and Bank of America for the ERM project. Leif succeeded Beames at Bof $A$, and Charlie Conroy began reporting to Leif. Leif and Conroy divided their duties. Leif handled the banking: Conroy spent most of his time at SRI. Eventually Conroy was spending so much time at SRI that in June 1953. he moved his office into SRI's Menlo Park headquarters and began to conduct all his business from there.

\section{The transistor study}

In the fall of 1952, SRI engineers Bart Cox, Jack Goldberg, and William H. Kautz set to work on the logical design of the system. One of the first and most significant decisions was whether to create the electronic logic using vacuum tubes, as was then common, or to use newly introduced transistors. Noe attended a Bel Laboratory seminar in New York City shortly after Bell announced the availability of its new transistors. It convinced him that SRI needed to consider the transistor option carefully. ${ }^{9}$ Transistors were reputed to have a low power drain and long life, and be of relatively small size and higher speed than the vacuum tubes then used for computer circuitry. The institute launched a major research study, beaded by Howard Zeidler, on the use of transistors. The study included trips to all of the companies that were producing transistors, including RCA, Sylvania, and Raytheon.

The SRI transistor study found a lack of consistent manufacturing quality, a shorter than anticipated life expectancy, less than presumed reliability, higher cost, and greater uncertainty regarding future prices and availability relative to vacuum tubes. ${ }^{14}$ In addition, the only transistors available were point-contact transistors; the junction transistor was not yet on the market.' SRI continued tube and transistor development in parallel until a decision was reached in April 1953 to use transistors in the ERM only to a limited extent. Electronic logic would be developed using tubes and wired programs for the prototype, but because the transistor problems were viewed as temporary, the possibility of transistorizing the final ERM was left open.

\section{Designing a machine-readable check}

In the summer of 1952, a team of engineers began working on a system to allow the ERM to "read" the account number and amount information on checks with minimal human involvement. The account number was to be preprinted and the check amount added during proofing. Analysis of the paper flow and observations of checks' journeys through the banks and clearing houses.led SRI to conclude that it was imperative the information on a check be transferred to the system as early in the process as possible. Ideally, the bank was hoping to find a system that would meet the following six requirements:

1. Change the check's appearance as little as possible. 
2. Use the front of the check so that only one run through the printing press would he required

3. Incur the same drying time as ordinary ink

4. Resist being rubbed off.

5. Be readily avallable

6. Use normal printing processes.

SRI's goal was to tind a method of coding that would cost the same as or only slightly more than the current check system.

At the time. the only technology that existed for relaying information to a computer was punched cards, which encoded information as holes. The idea that banks adopt an all punched-card check system was quickly ruled out as it was considered too great a change and too intrusive to the customer. ${ }^{26}$ Bank of America reiterated that the check was an emotional link to the customer and should be changed only minimally. ${ }^{18}$

The alternative to coding the check was to attach an encoded object to the check. Other organizations experimented with attaching a strip of paper to the check or placing the check, once it reached the bank, in a reusable envelope encoded with punched holes: or perforations.' These methods were referred to as "slave" or "carrier" methods.* SRI and Bof A quickly decided that the check itself. not some separate attachment, should be the medium **

Initially, fluorescent ink was thought to be the best method of directly encoding checks. Checks could be run below an ultraviolet light that caused the ink to fluoresce green, thereby making it "visible" to an input device connected to the computer. The ink met nearly every one of Bank of America's requirements: It was invisible to the customer, could be placed on the front of the check. and acted like standard ink. In addition, the ink was available at low oost from the nearby California Ink Company in Berkeley.

Although fluorescent ink was the front-runner and received serious consideration. functional flaws soon became

- The Chase Manhatian Bank and the First National City Bank of New York experimented with large-scale, carrier-method computer systems. Chase contracted with the Laboratory for Elcctronics, Inc., in Boston to create Diana. the "Goddess of the Chase." Cily Bank worked with an IT\&T subsidiary in Antwerp. Belgium. Although a protolype Diana was actually built, neither computer was ever successfully put into operation.

- Beise, as part of his constant communications with olher companies. explored the possitility of crcating a carrier system with International Telemeter Corporation. This liaison was managed by A.R. Zipf. The sustem was found to be too cumbersomc and expensive to be practical for the bank.
Shepard Laboratories*

Compagnie des Machine Bull

Magnetic drum

ElectroData Corporation* $\dagger$

Others

Marshall

Stamford Tool \& Die Corporation National Cash Register

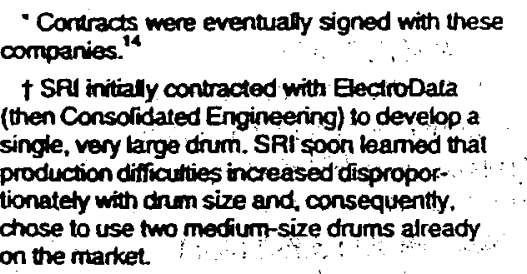
on the market. apparent. Pen and pencil marks could obscure the coding. as could opaque or sticky substances. Even more critical. the green and purple inks long used by bankers for cancellation stamps were naturally fluorescent and interfered with read. ings. ${ }^{27}$ SRI's Clark realized that to use fluorescent ink. all banks would have to change their cancellation mark ink an unlikely possibility. In addition. since the code was not visible to an operator in natural light, errors could not easily be detected. A third problem was interference from the natural oils on customers hands. The engineers also experimented with a zinc oxide-based ink. which had similar problems with interference from lubricating oils. :"

Concurrently, engineers working on the construction of the main machine were using reels of magnetic tape for the computer's external storage. This triggered the lahoratory scientists to investigate the use of magnetic ink for check printing, and they began work with the Williams Pigmenı Company to develop an ink for trials. Magnetic ink had its own set of drawbacks - very close contact was required between the check and the magnetic head used to read it. and the ink would be visible to the customer - but it had the advantage of being able to be read through such substances as bank cancellation stamps. ink. and scotch tape. In addition, magnetic ink was approximately one-fifth the cost of fluorescent ink. SRI set to work on the system and. hy late 1952. was able to present a working input check reader using a magnetic-ink bar code.

Morrin met with Beise in early 1953 to tell him Ihat SRI was convinced that the ERM system could only be run using magnetic ink. Betse was not pleased that there was only one way to solve his hanking problem, but agreed with what 


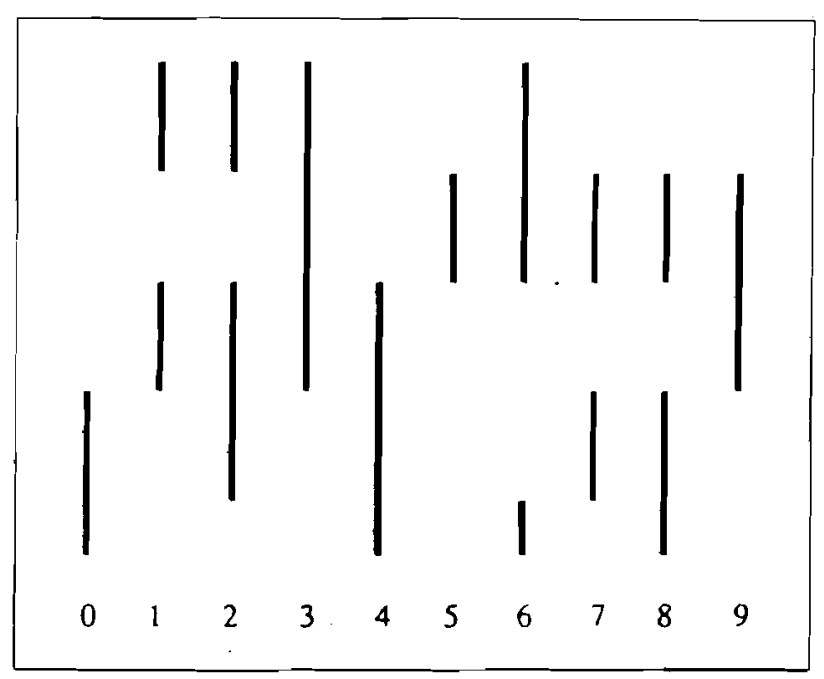

Figure 2. SRI's proposed bar code.

Morrin maintained was the only solution. Morrin later explained:

Unless the printed material on the checks provides [a] sufficient discrimination between the printing and all of the overprinting and is durable enough to withstand all of the transit handlings, the number of errors would be so great that the system equipment would have to be thrown out. In our laboratory work we built equipment to test error rates for both materials and type fonts for error rates. Magnetic material was the only one that gave an adequate signal-to-noise ratio. My firm judgment at the time...was based on these facts. ${ }^{25}$

Kenneth Eldredge, manager of SRI's new instrumentation and control systems laboratory, was put in charge of developing equipment for automatic check reading. Kamphoefner was in charge of the electronic aspects of the paper-handling program, and Paul Wendt headed the mechanical program. Other SRI engineers included Samuel Graf, in charge of chemical elements such as magnetic materials, ink formulation, and format tolerances; Philip Merritt, reader development; and Mendole D. Marsh, Carroll $M$. Steele, and Merritt, electronic design, including the nines error check (discussed later), control circuits interfacing with the IBM punch, and the output printer. ${ }^{29} \mathrm{~A}$ list of the principal engineers involved in the ERM program is presented in the sidebar on page 53.

\section{Magnetic-ink character recognition}

Initially, SRI planned to print the magnetic ink in a large bar code on the back of the checks ${ }^{1}$ using the code shown in Figure 2 . Bar codes were highly reliable but could not easily be checked for errors since they were not easily interpreted by humans. This made it difficult and time consuming to locate and correct a mistake made by the machine or in the printing process. Also, the approach left a visible bar code on the back of the check that changed the check's appear- ance, leading to some concern that customers might find it "spooky. "30.31

About this time, Eldredge had the opportunity to view an optical character reading system (OCR). This triggered him to start thinking about forming the magnetic ink into Arabic characters that could be read by both humans and computers. The scientists in Eldredge's lab created uniqui printed patterns for each character, which the machine was able to read and record. When the number sequence was scanned by a read head, the magnetic ink yielded a distinctive set of waveforms for each A rabic numeral. The idea was tested using simplified magnetic "characters" such as filled rectangles, circles, and triangtes so that any deviation from the expected waveforms could be easily detected. Using strips of 35-millimeter film corresponding to successive identical printed patterns on test documents, Eldredge's team achieved frame after frame of clean, identical waveforms with few variations, even when the printed patterns were totally obscured by ink or pencil. ${ }^{29}$ The priorities for the coding had changed, and bankers and engineers agreed that, because of accourntability. Arabic characters would be preferable to both bar codes and invisible ink.

SRI immediately realized that the magnetic-ink characier system was feasible; the only questions were how to implement the pattern-recognition circuitry and how much accuracy could be attained. Merritt, a young electronics engineer who was still taking courses at Stanford toward his $\mathrm{PhD}$, assumed responsibility for implementing the wave form-recognition circuitry required for Eldredge's proposed reader. Mernitt successfully designed the system referred to as Magnetic Ink Character Recognition (MICR), which was adopted as the machine language for the ERM. The language consisted of a 10-digit font with four additional symbols for specific functions. The ink was read as the char acters were scanned horizontally under a single, wide magnetic head. ${ }^{29}$

\section{Paper handling}

While the MICR work was proceeding. A. Kaehler began work on a simple paper-handling system that was to pass bar-coded checks through a reader at the proof ma. chine as input to the ERM. Checks processed by the ERM in random order needed to be arranged by account number to be returned to the proper customer with the monthly statement. A high-speed check sorter was needed to cut the fast-growing labor cost of manual sorting and to meet vol. ume demands. The sorting machine had to be able to sori thousands of checks each day as they were spit out randomiy by the ERM. These checks had a variance of almost two to one in length, width, and thickness. Furthermore, the checks had already been circulated by the public, which often folded, ripped, stapled, or taped them. ${ }^{32}$ Building on Kaehler's work, William Noon, another SRI engineer, suc. cessfully developed a more advanced sorting system, includ. ing a vacuum-driven check feeder, and transport, gating, and

- The ERM was still using the magnetic har-code system when announced in 1955. Shortly thereafter. it was suitched over to MICR 


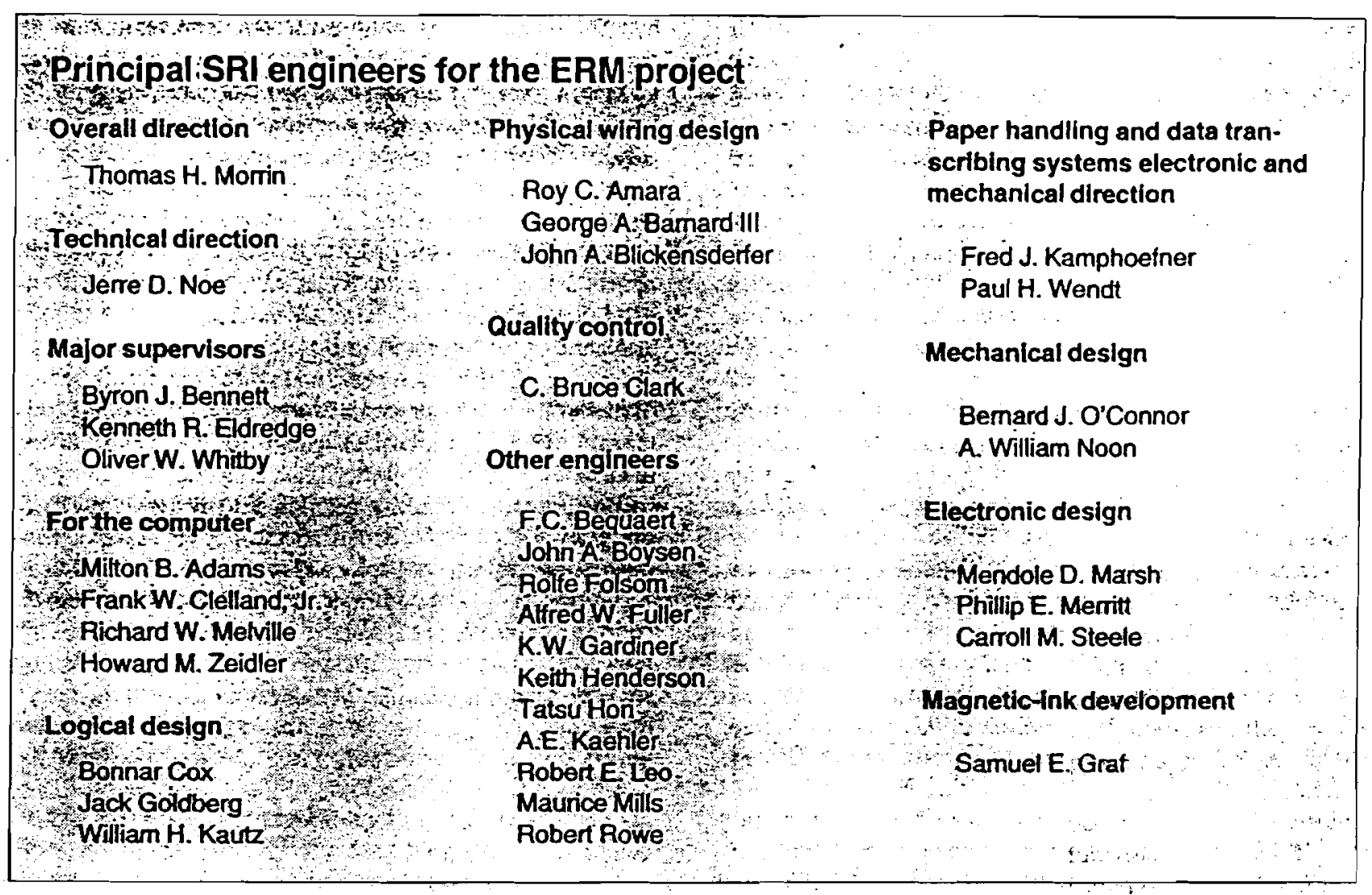

stacking components that separated and organized batches of several thousand checks at a rate of 600 checks per minute.

Batches of processed checks were physically sorted by account number by transporting each check into one of ten slots according to the first digit on the check. The same process was repeated for the next digit in the account number at this level and so on for eight levels until all the checks were correctly sorted. Paul Wendt, supported by Bernard J. $\mathrm{O}^{\prime}$ Connor and Tatsu Hori, later redesigned the feeder module so it was more flexible and could process at even higher speeds. $^{23}$

Both the MICR system and check sorter were solutions to practical problems that arose as the SRI engineers set out to solve Bank of America's paper-handling crisis, but these two technological advances were to become the most long lasting and important contributions of the ERM program. In 1961, after examining many other scientific achievements, the US Patent Board granted Ken Eldredge the singular honor of receiving the 3,000,000th United States patent for his work with character recognition. ${ }^{33}$ In addition, the American Bankers Association Technical Subcommittee on the Mechanization of Check Handling, after spending two years traveling extensively and evaluating all known methods of check reading, in July 1956 unanimously recommended MICR as the Common Machine Language for the banking industry. MICR standard specifications and type font were decided by 1959 , and by 1967 virtually every check in the United States (as well as in numerous foreign countries) was printed with MICR. The system remains in place today. ${ }^{34}$

\section{The traveler's check program}

By the summer of 1954, Eldredge and Kamphoefner felt they had a reliable check reading sistem and began to search for a medium to test MICR. Bank of America already was using the traveler's check program to test an OCR system, and experiments were conducted using a reader developed by Intelligent Machine Research of Arlingıon. Virginia. Although the OCR machine was an impressive achievement for its time, the reader had two serious flaws that precluded its use by Bof A: excessive downtime due to temperature and tolerance problems, and interference stemming from handwritten signatures infringing on the area of the serial number. ${ }^{29}$ Eldredge's work on character recognition was concurrent with the OCR program, and it was decided that the traveler's check program would be an ideal way to test both MICR and the paper-handling system.

The traveler's check program was considered a fitting test run for MICR and the sorter for many reasons: ${ }^{29}$

- Traveler's checks were printed only at a few specialized printing houses, permitting tight control of font and printing tolerances by companies accustomed to rigid standards.

- All traveler's checks were the same dimension 
- The serial numbers on traveler's checks were larger than on regular checks and could be restyled slightly without changing the basic format.

- Traveler's checks were a self-contained system in which the existing processing method could operate in parallel as a control during the break-in period.

- A check digit could be added easily to the serial number to ensure the detection of any reading errors.

- As the amount on traveler's checks was preprinted, it would not need to be added after the check was brought to the depositor's bank.

Finally, if the traveler's check program was successful, there would be an immediate payoff even using only the single prototype machine, as the use of MICR would replace the cumbersome and costly punched-card system Bof $A$ had in place at the time.

To ensure accuracy, a system called the nines check was used. Each traveler's check had a nine-digit serial number and an additional 10th digit indicating the check's denomination. An 11th digit, when added to the sum of the other 10 digits, made the total evenly divisible by nine. As each check : was read, the digits imprinted on the check were totaled by the machine. If the total was not divisible by nine, the check was rejected by the system and handled by one of the remaining bookkeepers. ${ }^{27} 30.31$

To test the system with worst-case scenarios, the engineers severely damaged many of the checks in the same ways customers often inadvertently mangle their checks. These included marring the checks with stamps, ink, dirt, finger marks, rips; and tape. The engineers also subjected the checks to a "crumple test": wadding the check into a small ball, then flattening it out and running it through the machine. $^{3031}$ The traveler's check scanner and MICR system interpreted and sorted even the most damaged of these checks.

In the spring of 1955, SRI demonstrated a working traveler's check scanner. ${ }^{14}$ SRI's work with nonstandard paper handling and the development of MICR had been very successful. With the two technologies combined, under extreme conditions the traveler's checks theoretically could be processed at a rate of up to 2,000 per minute. The actual rate of operation was limited to 100 checks per minute by the standard IBM card punch that produced cards for reconciliation to be used by Bof A's existing traveler's check clearing operation. ${ }^{14}$ The traveler's check system proved a superb showcase for MICR and the paper-handling advances. By June 1955, more than 300,000 traveler's checks had been scanned through the system.*

\section{Construction of the ERM}

In March 1954, the majority of the ERM design work was considered to be complete, and construction began in SRI buildings $410 \mathrm{~A}$ and $410 \mathrm{~B}$, following the installation of refrigeration equipment. ERM construction was supervised

* This section was written with considerable input from Dr. Fred J. Kamphoefner, who wrote his memoirs of magnetic-ink development and the traveler's check program for this project. by SRI's Richard Melville and took approximately 15 months tó complete. There were five major stages. The first. in March, was the installation of elaborate refrigeration equipment, including heat exchangers, blowers, and tem. perature-control materials. The second stage, in April 1954. was the arrival of a motor alternator to supply power for the ERM. The ERM required 50 kilowatts of direct current power, which had to be processed using a special plant that converted the power from the standard commercial alternating current. The plant also maintained constant voltage and amperage to shield the system from power surges."* The third stage, between May and July of 1954, saw the heart of the system - the magnetic drums, ElectroData magnetic tapes, and Bendix circuit packages - begin arriving. During the fourth stage, in November 1954, the paper-handling and sorting procedures became reliable. Finally, in March 1955 . the Shepard printer was installed in a separate soundproofed room.

During construction, engineering changes were made constantly to improve system reliability and functionality. Howard Leif and others at Bank of America grew restless with the continual changes and developments to the seemingly never-ending ERM project, and finally, in the spring of 1955, Beise and Leif said "enough" and declared the design of the machine complete. Plans were made to announce the system in September 1955. Although adjustments were to be permitted after the official presentation. the machine was to be constructed "as is" for the demonstration.

Completing the ERM's construction under the bank's time constraints proved to be a challenging task. The time pressure was significant, and as September neared engineers worked in shifts around the clock. The most serious problems came with debugging the hardwired machine. Parts of the hardwiring were being put together before others were even mapped out. Adjustments were being made constantly to avoid problems. By the time the system was demonstrated to the public, the carefully developed logic diagrams were obsolete. So many undocumented changes had been made to the hardwiring that complete documentation could not be passed on to a manufacturer. This later proved to be a serious problem for the system manufacturer that was selected.

Several departures were made from the original plans First, due to time constraints and operational concerns, the final ERM was a bookkeeping machine only. Despite the bank's desire for automated proofing and many engineers' interest in combining the two functions, the idea turned out not to be feasible. Checks continued to be proofed at the branches before being sent to the ERM centers.

\footnotetext{
** According to several SRI engineers, the power system created many mishaps: "One particularly impressive incident involved the $300 \mathrm{~V}$ de power supply. The dc supplies also had large capacitor banks in their output circuitry, and on one rainy day, moisture created a short circuit into which the entire considerable energy of the $300 \mathrm{~V}$ bank was discharged. Fortunately, the damage was rela. tively minor, but henceforward it was forbidden to use the term "fire it up when referring to turning the system on!" is
} 
A second change was in the sorting process. Initially SRI had hoped to combine the high-speed sorter with the main ERM system so that bookkeeping and sorting could be handled as a continuous process. Again, with the time and operational constraints, this was impossible. The SRI sorter was used after the ERM as a separate system, however, to sort checks to customers.

Third, in the original plan SRI's prototype was to be moved to the Berkeley branch for a test run. As the machine began to be assembled, Bank of America searched for a closer location and selected the Hester branch in San Jose. In early 1955, a decision was made, with the advice of Jerre Noe, not to move the enormous computer at all. ${ }^{9}$ Tests were run at SRI by bringing in checks from a nearby branch - a more realistic plan than moving 50,000 pounds of computing equipment to a town 20 miles away.

The final ERM computer contained 8,200 vacuum tubes, 34,000 diodes, five input consoles with electronic reading devices, two magnetic-memory drums, a check sorter, a high-speed printer, a power-control panel, a power plant, a maintenance board, 24 racks holding 1,500 electrical and 500 relay packages, 12 magnetic-tape drives, each able to handle 2,400-foot tape reels, and a refrigeration system. The ERM was equipped with more than one million feet of wire, weighed a hefty 25 tons, and occupied 400 square feet. ${ }^{14}$

The ERM was designed to automate the bookkeeping details of 50,000 checking accounts utilizing a $16 \times 20$-inch drum memiory and wired program. The machine functioned tas follows. A check deposited at a BofA branch was proofed into an "on us" bin and the batch forwarded to the local ERM center. Here one of the operators read the check, entered its.amount on a keyboard, and dropped it into a siak The ERM first scanned the check for the magnetized ac: count number and accessed the current balance in that file in the magnetic-drum memory. The operator confirmed the information by pressing a bar. In a standard transaction, the process was completely automated after this point. The machine checked to see if there was a stop payment or hold on the account funds. If so, the machine refused to process the check. If not, the ERM subtracted the amount on the check from the amount in the account. If this total was negative, the check was rejected and sent to a supervisor for further action. Assuming a positive balance, the new balance was replaced in storage and the account number and debit amount noted in temporary storage. All this information was then transferred to magnetic tape and printed on a paper tape.

The only information contained in the machine's memory was the account number and current balance. The account number, name, address, checks by amount and date, and current balance were also retained on the magnetic tape. Once a month a technician removed each magnetic tape and connected it to a printer, which printed out a record of all account activity for each account, plus the service charge the system had calculated.'

\section{Announcing ERMA}

In early 1955, Conroy, Leif, and the other Bank of America representatives began to shift their focus away from the construction toward the grand public announcement of the ERM system. The announcement, staged down to the last detail, included a name change for the system. The public relations office at Bank of America decided that "ERM" was too technical sounding and potentially too intimidating to customers. After much brainstorming (and to the engineers' considerable dismay), the machine was rechristened the Electronic Recording Machine - Accounting, to be known as "ERMA."*

As part of the preparations for the announcement of ERMA, SRI put together a detailed publicity description of the development, and Bof A generated dozens of press releases and prepared photographs for use by magazines, television, and newspapers. The literature emphasized the extraordinary accomplishment Bank of America considered it had achieved. The fact sheet distributed to the press described ERMA as "the biggest single advance in bank account bookkeeping in the history of banking," and stated that "the invention of ERMA was the climax of an unrelenting search for a new; method to help Bank of America to meet the challenge of the ever-growing banking needs of California's surging economy. "?2 The literature was careful to explain that while the nine bookkeepers who worked on each ERMA would replace more than 50 traditional bookkeepers, ${ }_{1}^{1}$ no one would lose his or her job. The differences would be made up by attrition and lateral job transfers. One of the few areas downplayed was how the ERMA system would affect customers (e.g., the new account numbers); Brief mention was made of the bar codes on the back of each check, and customers were cautioned not to lend their blank checks to anyone.

September 22, 1955, was officially designated "ERMA Day" at Bank of America. Employees were notified about ERMA a few days before the worldwide announcement, but letters were not sent to stockholders until ERMA Day. The introduction to ERMA was held at SRI headquarters in Menlo Park. To avoid any aspect of the story leaking, the press was brought in from San Francisco on buses provided by BofA. The presentation was conducted by Clark Beise (by then Bank of America president) and Tom Morrin of SRI. At the demonstration, Beise spoke of the great contribution the machine would be making to Bank of America where it was eagerly awaited, and to the banking community in general. Morrin emphasized the magnitude of the engineering accomplishment and demonstrated the system. ${ }^{* *}$

\footnotetext{
- SRI recommended that BofA adopt the name FINAC, an ab. breviation of financial accounting, as the official computer title. The engineers felt this was a more appropriate designation because "the equipment calls for too beavy an investment for light treatment by name." 36

* By ERMA Day, the sorter was still not performing reliably. Engineers worked on the machine right up until ERMA's unveiling to the public. Before Morrin demonstrated the machine to the joumalists, he bad an SRI engineer in the back of the room indicate with a thumbs-up signal that it was performing stably and the show could go on. The demonstration went perfectly and the press never suspected the sorter was less than ideal. That evening, at a private showing for SRI employees, the sorter went haywire and spewed checks all over the room at the engineers.
} 


\section{Development of ERMA}

Neither man named the firms that had collaborated on the project or the costs incurred.

The ceremony was attended by an impressive list of journalists, including the financial editors of newspapers and wire services, California business syndicate writers, and writers from The New York Times, Life, Forlune, Newsweek, and Business Week. ${ }^{14}$ Bank of America's attention to the media paid off in a barrage of articles in leading national journals lauding the accomplishment in glowing terms.

\section{Discussion}

It is crucial to note that "the biggest single advance...in the history of banking" did not come from a traditional business-equipment manufacturer. It took the pressure of check growth on the world's largest bank combined with an innovative research institute to produce the machine. For business-machine manufacturers, the 1950 status quo had been fine. Emerging computers seemed more attuned to computation than paper processing, and banks were forced to buy considerable quantities of proof machines to keep up with the flow of checks. The manufacturers seemingly had little to gain by risking time and capital in a speculative research and development, project.

Bank of America, in contrast, was desperate, driven by need, not by preserving market share. The check-handling crisis had become so severe that Beise feared it would impinge on expansion. Forced to search for a new technological solution, BofA was open to all suggestions. Beise, as a sponsor determinied to solve the problem, was willing to invest the necessary capital to prove the solution possible. Once the design of the machine had adequate functionality, Beise, Leif, and Conroy, sensing a solution at hand, decided. that spending more money was unproductive and so demonstrated the model "as is."

SRI tumed out to be the perfect panner for Bank of America. SRI was interested in becoming involved with computers, it needed the project, and it was less than an hour away from BofA headquarters. In addition. secrecy was easily maintained. The SRI team, on the basis of a thorough understanding of the requirements, designed and built four new components of the banking-oriented system:

1. An encoding system to enable electronic versus manual handling of all check-processing activities.

2. A check reading system that allowed detection of the necessary information from any size check under normal usage.

3. An encoding system to imprint the amount of the check in an electronically readable format.

4. A control system for incoming checks and a computer-based bookkeeping system to carry out necessary bookkeeping procedures.

SR I's and Bank of America's achievements were considerable. The two companies put together a computer-based check-processing system that was a radical advance from anything the business-machine manufacturers had consid- ered. They broke the dominant check-processing design, which had been improved only incrementally for 100 years. Although the final SRI system was a bookkeeping machine only, the new innovation forged the potential for combining the proofing and bookkeeping clerical activities into a single system and providing ready access to account balances throughout the day.

Along the way the goals had been changed from creating a production machine to devising models of how a checkprocessing system could work. ERMA was not complete as a total working computer system, but complementary innovations had the components of a "total system." It relied on bar codes on the back and on the operator checking the account number. The traveler's checks system had proven the reliability and operational value of MICR. Eldredge's character recognition system had established the ability of magnetic-ink characters to be used for check processing. ERMA proved the ability to process normal checks encoded with MICR and the efficiency of centralizing bookkeeping.

Both companies were represented by outstanding leadership. Clark Beise was a, thoughtful, visionary man who had a futuristic view of banking: Although he had no formal training in technology, he was able to see it as the solution to his problems and to turn to those who did know computers. Beames, Conroy, and Leif worked more closely with SRI. Again, these men were short on technical experience, but they knew banking inside out and had a strong systems point of view. Conroy provided the impetus to ensure that bank procedures were understood at the level of detail needed and that the rich assortment of technologists solved individual technical issues within the constraints of overall bank check-processing requirements. At SRI, Bank of America was, well-served by the leadership of Tom Morrin, Jerre Noe, Oliver Whitby, Ken Eldredge, Jack Goldberg. Fred Kamphoefner, and others.

$\mathbf{T}$ he development of the ERMA system came as a huge surprise to the manufacturing and banking communities. Journalists, bankers, and manufacturers all rushed to find out more about this revolutionary machine that was rumored to have fundamentally changed banking. Most surprising was that the newest technology was not coming from a supplier of equipment, but from a user - Bank of America.

Bank of America's leadership was crucial in forcing bankers and manufacturers to consider electronic options. In the fall of 1955, after the announcement, Beise was able to sit back and enjoy the rush of companies queuing up for the chance to manufacture his machine.

\section{Acknowledgments}

We would like to express our appreciation to the other members of the Harvard Business School MIS History Project: Richard G. Canning, Walter M. Carlson, Duncan G. Copeland, Philip H. Dorn, George Glaser, Richard O. Mason, and Frederic $G$. Withington. 


\section{References}

1. E.L. Van Deusen, "The Coming Victory Over Paper," Fortune, Oct. 1955 , p. 132.

2. "How Banking Tames Its Paper Tiger," Business Revien', Phil adelpbia Federal Reserve Bank, May 1960.

3. E.D. Spina, "Magnetic Character Recognition," Report to In ternational Standards Organization Technical Committee/97 Working Group C on Character Recognition by US Delegation, Oct. 1962, p. 2.

4. A.R. Zipf, interview at Oroville, Calif., Oct. 23, 1989. Harvard Business School, Boston.

5. "Srudy of Check Coliection System," Report of the Joint Committee on Check Collection System to the American Bankers Association, Association of Reserve City Bankers, Conference of Presidents of the Federal Reserve Banks, June 15, 1954, p. 1.

6. "Sixty-four Years of Growth of Bank of America NT \& SA," Bank of America, San Francisco, 1968

7. "Bank of America NT \& SA and Bankamerica Corporation: A Brief Historical Sketch," Bank of America, San Francisco, Sept 1974.

8. J. Schermerhon, "S. Clark Beise dies at 91; headed BofA," San Francisco Examiner, Oct. 25, 1989.

9. J.D. Noe, interview at Seattle, Oct. 20, 1989, Harvard Business School, Boston.

10. Memorandum to History Files, from W. B. Gibson, SRI, Menlo Park, Calif., 1954.

11. "Our Future with Erma," The Bankamericar, Bank of America, San Francisco, Oct. 1955.

12. "A Resume of the Development of the Eleatronc Recording Machine (ERM)," SRI. Menlo Park. Calif., July 20, 1955.

13. "The Development of ERMA," SRI, Menlo Park. Calif., Sept. 1955.

14. "A History of the Electronic Recording Machine (ERM)." SRI, Menio Park, Calif., June 1, 1955.

15. Memorandum to T.H. Morrin, from O. Whitby, "Project X104, " SRI, Menlo Park, Calif., Nov. 14, 1950.

16. Memorandum to T.H. Morrin, J. Lovewell, and J. Noe, from O Whitby, SRI, Menlo Park, Calif., July 27, 1950.

17. Menuorandum to T.H. Morrin, from J.D. Noe, SRI, Menlo Park, Calif., July 17, 1950.

18. A.R Zipf, telephone interview, May 11, 1991, Harvard Business School, Boston.

19. O. Whitby, "Project Diary \#385: Background Work on Project," SRI, Menlo Park, Calif., May 30, 1951

20. "Appendix A: Specifications of an Electronic Recording Machine (ERM)," SRI, Menlo Park, Calif., Jan. 21, 1952.

21. A.R Zipf, Eastern Trips: Reports to the Managing Commitree of Bank of America, Bank of America, San Francisco. May 1954 to Mar. 1958.

22. O. Whitby, “Project Dateline," SRI, Menlo Park, Calif., 1951

23. T.H. Morrin, interview at San Francisco, Oct. 18, 1989, Harvard Business School, Boston.
24. T.H. Morrin, "Outline of Memoirs of Thomas H. Morrin on 'ERMA,' 1949-1957," SRI, Menlo Park, Calif., 1973.

25. T.H. Morrin, letter to authors, Harvard Business School, Boston, June 28, 1991.

26. J.A. Kley, interview at Naples Fla., Nov, 30, 1989, Harvard Business School, Boston.

27. FJ. Kamphoefner, interviews at Menlo Park, Calif., July 3, Oct 18, 1989, Harvard Business School, Boston.

28. C.B. Clark, telephone interview, Jan. 24, 1990, Harvard Business School, Boston.

29. T.H. Morrin, letter to autbors, Harvard Business School, Boston, Feb. 5, 1990.

30. B. Cox, interview at Menlo Park, Calif, Oct. 18, 1989, Harvard Business School, Boston

31. J. Goldberg, interviews at Menlo Park, Calif., July 3, Oct. 18, 1989, Harvard Business School, Boston.

32. "ERMA: Electronic Recording Machine, Aocounting," SRI, Menlo Park, Calif., Sept. 1955, p. 11.

33. US Patent No. $3,000,000$, issued to Kenineth $R$. Eldredge and General Electric Co., Washington, D.C., Sept 12,1961 .

34. J.L. McKenney, "Developing a Common Machine Language for Banking: Lessons trom History," working paper, Harvard Business School, Boston, 1991.

35. RA. Folsom, letter to authors, Harvard Business School, Bos ton, June 7, 1992.

36. Memorandum to J.R. Davis and Fred Yeates, from H.A. Leif, "Formal Name for the ERM," Bank of America, San Francisco, Aug. 8, 1955

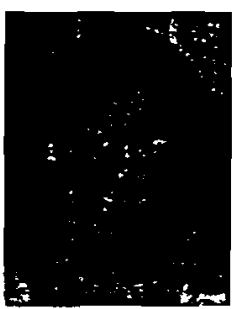

Amy Weaver Fisher is a student at the Harvard Law School. She worked as a research associate at Harvard Business School from 1989 to 1992 . She is a graduate of Wellesley College.

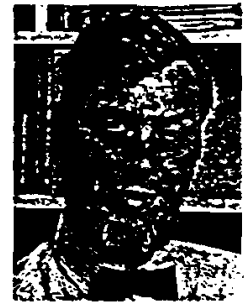

James L. McKenney is John G. McLean Professor of Business Administration at Harvard Business School, where he has taught since 1960 . He is the author of many books and articles, including Cor porate Information Systems Managemen - The Issues Facing Senior Executives (with F. Warren McFarlan and James 1

Cash). McKenney is the leader of the Harvard Business School MIS History Project and is a founder of the Computer Museum in Boston.

McKenney can be reached at Harvard Business School, Boston, MA 02163. 